\title{
GEL EKSTRAK BUAH NAGA SUPER MERAH (HYLOCEREUS COSTARICENSIS) DAN UBI JALAR UNGU SEBAGAI ALTERNATIF PEWARNA (DISCLOSING SOLUTION) ALAMI PLAK GIGI
}

\author{
SUPER RED DRAGON FRUIT (HYLOCEREUS COSTARICENSIS) AND PURPLE \\ SWEET POTATO EXTRACT GEL AS NATURAL ALTERNATIVE DENTAL PLAQUE \\ DYE (DISCLOSING SOLUTION)
}

\section{Fahmi Said $^{1 *}$, Ida Rahmawati², Triwiyatini $^{3}$}

1,2Politeknik Kesehatan Banjarmasin

Jl. Garuda No.21 Banjarbaru. Indonesia

${ }^{3}$ Politeknik Kesehatan Semarang

Jl.Tirto agung, Wonodri, Kec. Semarang Sel., Kota Semarang. Indonesia

*Email :fahmialai1959@gmail.com

\begin{abstract}
Dental plaque is a thin layer that is colorless, not easily seen and is the cause of dental caries. To see dental plaque needed Disclosing solution. One of the natural ingredients that has been investigated for its effect in coloring plaque is betacyanin, which is contained in super red dragon fruit (Hylocereus costaricensis) and purple sweet potato (Ipomoea batatas var Ayamurasaki). This study aims to formulate dragon fruit gel extract that suits. The research was carried out by extracting dragon fruit, formulating in the form of gel, tested the physical properties of the gel, conducted a toxicity test with shrimp larvae, and measured the plaque index on 40 respondents, 20 respondents each in Poltekkes Banjarmasin and 20 respondents in the Poltekkes Semarang. The results showed that the average plaque score in the treatment of dragon fruit was 2.6470, slightly higher than the plaque score in the treatment with purple sweet potato which was 2.5165. Conclusion of Independent t test analysis, found a mean different (average difference) of 0.13050, with known $t$ value of $0.517, p$ value (probability value) of the test shows $p=0.608$, so it is greater than a 0.05 or $(p=0.608>$ a 0.05) meaning that there is no difference in effectiveness between dragon fruit gel extract and purple sweet potato gel extract. It is recommended to identify plaque score using both gel extracts because both can detect score plaque and are based on natural ingredients not using chemicals
\end{abstract}

Keywords: Dragon-Fruit; Disclosing-Solution; Index-Plaque; Purple-Sweet-Potato; Toxicity-Test

\begin{abstract}
ABSTRAK
Plak gigi merupakan lapisan tipis yang tidak berwarna, tidak mudah dilihat dan merupakan penyebab karies gigi. Untuk melihat plak gigi diperlukan Disclosing solution. Salah satu kandungan bahan alami yang telah diteliti efeknya dalam mewarnai plak adalah betasianin, yang terkandung dalam buah naga super merah (Hylocereus costaricensis) dan Ubi jalar ungu (Ipomoea batatas var Ayamurasaki). Tujuan penelitian ini untuk memformulasi ekstrak gel buah naga. Penelitian dilakukan dengan melakukan ekstraksi buah naga, memformulasi dalam bentuk gel, mengujian sifat fisik gel, uji toksisitas dengan larva udang, dan mengukur indeks plak pada 40 responden, 20 orang responden di Jurusan Teknik Laboratorium Medik Poltekkes Banjarmasin dan 20 orang responden di Jurusan Teknik Laboratorium Medik Poltekkes Semarang. Hasil Penelitian terlihat bahwa plak skor rata rata pada perlakuan buah naga sebesar 2,6470 sedikit lebih besar dibandingkan plak skor pada perlakuan dengan ubi ungu yaitu sebesar 2,5165. Kesimpulan analisis Independent t test, ditemukan mean different (selisih rata-rata) sebesar 0,13050, dengan diketahui nilai t hitung sebesar 0,517, $p$ value (nilai probabilitas) dari uji tersebut menunjukkan $p=0,608$, sehingga lebih besar dari a 0,05 atau $(p=0,608>$ a 0,05$)$ artinya tidak ada perbedaan efektivitas antara ekstrak gel buah naga dan ekstrak gel ubi jalar ungu. Saran untuk identifikasi plak skor menggunakan kedua ekstrak gel tersebut karena sama-sama dapat mendeteksi plak skor dan berbahan dasar alami tidak menggunakan bahan-bahan kimia
\end{abstract}

Kata kunci: Buah naga; disclosing solution; plak indeks; ubi jalar ungu; uji toksisitas 


\section{PENDAHULUAN}

Plak gigi merupakan lapisan tipis yang tidak berwarna, sehingga tidak dapat dilihat dengan mata (1). Oleh karena itu, proses pembersihan gigi harus dilakukan sebaik mungkin, dan harus membersihkan seluruh permukaan gigi. Meski demikian, masih terdapat daerah yang sulit dijangkau oleh pembersih gigi sehingga plak tetap ada di daerah tersebut dan terus menumpuk hingga akhirnya akan menimbulkan karies (2). Oleh sebab itu, diperlukan suatu bahan yang dapat membantu melihat plak gigi, yaitu disclosing solution. Namun, disclosing solution berbahan kimia memliki berbagai kelemahan, yaitu rasa yang tidak enak sehingga kurang disukai, dapat mewarnai mukosa selama beberapa jam sehingga dapat menimbulkan rasa malu bagi pasien yang akan segera beraktivitas setelah menggunakannya, dan bahan pewarna yang memiliki potensi sebagai bahan karsinogen (3).

Beberapa kelemahan dari disclosing solution berbahan kimia tersebut menjadi dasar pengembangan disclosing solution berbahan alami yang dapat digunakan masyarakat sebagai bahan pewarna plak. Bahan alam memiliki kelebihan yaitu tersedia dalam jumlah melimpah dan memiliki tingkat keamanan yang tinggi. Bahan alam yang memiliki warna mengandung golongan fenolik terutama subgolongan antosianin yang umumnya memiliki kemampuan sebagai antioksidan. Beberapa bahan alami yang mengandung pigmen warna antosianin (merah) dan betasianin (merah-ungu)yaitu ubi jalar ungu dan buah naga (4). Salah satu tumbuhan yang juga mengandung pigmen betasianin yang tinggi adalah buah naga super merah (Hylocereus costaricensis). Kandungan pigmen betasianin inilah yang menyebabkan daging buah naga super merah berwarna merah keunguan. ${ }^{5}$ Betasianin termasuk dalam kelompok pigmen betalain yang berfungsi sebagai antioksidan, anti-inflamasi, antivirus, antikarsinogenik, antibakteri, dan antiprotozoal $(6,7)$. Penelitian ini bertujuan memformulasi ekstrak gel buah naga yang sesuai persyaratan sifat fisik gel, mengetahui keamanan ekstrak gel buah naga berdasarkan parameter uji toksisitas, dan mengetahui kemampuan ekstrak gel buah naga sebagai pewarnaan plak gigi.

\section{BAHAN DAN METODE}

Penelitian ini menggunakan rancangan penelitian True eksperimental dengan Postest Only Control Group Design. Dalam desain ini, terdapat dua kelompok yang masing-masing dipilih secara random. Kelompok pertama diberi perlakuan buah naga dan kelompok lain diberi perlakuan ubi jalar ungu (8). Penelitian dilakukan dengan melakukan ekstraksi buah naga, memformulasi dalam bentuk gel, melakukan mengujian sifat fisik gel, melakukan uji toksisitas dengan larva udang, dan mengukur indeksplak pada 40 responden dengan dua kali perlakuan, masing-masing 20 orang responden di Jurusan Teknik Laboratorium Medik Poltekkes Banjarmasin dan 20 orang responden di Jurusan Teknik Laboratorium Medik Poltekkes Semarang.

\section{HASIL DAN PEMBAHASAN}

Tabel 1. Kategori Plak Skor dengan Menggunakan Ekstrak Gel Solution Buah Naga dan Ubi Jalar Ungu (Banjarmasin)

\begin{tabular}{lll}
\hline \multicolumn{1}{c}{ Variabel } & $\mathrm{n}$ & \multicolumn{1}{c}{$\%$} \\
\hline Buah Naga & & \\
Baik & 6 & 30 \\
Sedang & 8 & 40 \\
Buruk & 6 & 30 \\
Ubi Jalar Ungu & & \\
Baik & 1 & 5 \\
Sedang & 17 & 85 \\
Buruk & 2 & 10 \\
Total & $\mathbf{2 0}$ & $\mathbf{1 0 0}$ \\
\hline
\end{tabular}

Tabel 2. Uji Independent Samples Test Ekstrak Gel Solution Buah Naga dan Ubi Jalar Ungu terhadap plak skor (Banjarmasin)

\begin{tabular}{cccc}
\hline $\begin{array}{c}\text { Mean } \\
\text { Difference }\end{array}$ & $\mathbf{t}$ & $\mathbf{9 5 \%} \boldsymbol{C I}$ & $\boldsymbol{p}$ value \\
\hline 0.13050 & 0.517 & $0.38213-$ & 0.608 \\
& & .064313 & \\
\hline
\end{tabular}

.Dari analisis diatas dimana pada uji beda pada rata-rata plak skor dengan perlakuan buah naga dan ubi ungu, dengan analisis Independent $t$ test, ditemukan mean different (selisih rata-rata) sebesar 0,13050, dengan diketahui nilai $t$ hitung sebesar $0,517, \quad p$ value (nilai probabilitas) dari uji tersebut menunjukkan $p=0,608$, sehingga lebih besar dari a 0,05 atau $(p=0,608>$ a 0,05$)$, dengan 
kata lain tidak terjadi perbedaan efektivitas perlakuan buah naga dan ubi ungu terhadap plak skor, walaupun secara gambaran deskriptif terlihat bahwa plak skor rata rata pada perlakuan buah naga sebesar 2,6470 lebih besar dibandingkan plak skor pada perlakuan dengan ubi ungu yaitu sebesar 2,5165. Namun selisih perbedaan atau mean difference nya belum menunjukkan perbedaan secara signifikan, atau dapat dikatakan bahwa kedua perlakuan tersebut relatif sama dalam perubahan plak skornya.

Tabel 3. Kategori Plak Skor dengan Menggunakan ekstrak Gel Solution Buah Naga dan Ubi Jalar Ungu (Semarang)

\begin{tabular}{lll}
\hline \multicolumn{1}{c}{ Variabel } & $\mathrm{n}$ & \multicolumn{1}{c}{$\%$} \\
\hline Buah Naga & & \\
Baik & 19 & 95 \\
Sedang & 1 & 5 \\
Buruk & 0 & 0 \\
Ubi Jalar Ungu & & \\
Baik & 1 & 5 \\
Sedang & 17 & 85 \\
Buruk & 2 & 10 \\
Total & $\mathbf{2 0}$ & $\mathbf{1 0 0}$ \\
\hline
\end{tabular}

Tabel 4. Uji Independent Samples Test Ekstrak Gel Solution Buah Naga dan Ubi Jalar Ungu terhadap plak skor (Semarang)

\begin{tabular}{cccc}
\hline $\begin{array}{c}\text { Mean } \\
\text { Difference }\end{array}$ & $\mathrm{T}$ & $\mathbf{9 5 \%} \mathrm{CI}$ & $\boldsymbol{p}$ value \\
\hline 1.16150 & 1.035 & $0.38213-$ & 0.307 \\
& & .064313 & \\
\hline
\end{tabular}

Dari analisis diatas dimana pada uji beda pada rata-rata plak skor dengan perlakuan buah naga dan ubi ungu, dengan analisis Independent $t$ test, ditemukan mean different (selisih rata-rata) sebesar 0,16150, dengan diketahui nilai $\mathrm{t}$ hitung sebesar 1.035, $p$ value (nilai probabilitas) dari uji tersebut menunjukkan $p=0,307$, sehingga lebih besar dari a 0,05 atau $(p=0,307>$ a 0,05$)$, dengan kata lain tidak terjadi perbedaan efektivitas perlakuan buah naga dan ubi ungu terhadap plak skor, walaupun secara gambaran deskriptif terlihat bahwa plak skor rata rata pada perlakuan buah naga sebesar 1,1605 lebih besar dibandingkan plak skor pada Buah naga dan ubi ungu merupakan bagian tanaman yang mengandung pigmen warna.
Buah naga mengandung metabolit primer yang dihasilkan dari pembuahan pada tanaman naga super merah (Hylocereuscostaricensis). Ubi ungu merupakan hasil penyimpanan cadangan makanan. Pada buah naga merah terkandung pigmen warna merah, sedangkan pada ubi ungu terkandung pigmen warna ungu. Pigmen warna kedua sampel tersebut berasal dari senyawa golongan antosianin. Pigmen warna tersebut berasal dari alam, sehingga bersifat tidak toksik dan menjadi alternatif sebagai disclosing solution. Pada kedua gel diketahui homogen dan tidak terdapat partikel kasar. Viskositas atau kekentalan dari kedua gel tidak jauh berbeda dan sesuai dengan literatur (9). Gel yang terlalu kental akan sulit mengalir, sedangkan gel yang terlalu cair akan sulit untuk menempel saat diaplikasikan(10).

Dibandingkan yang berdaging putih, buah naga berdaging merah memilki kelebihan karena mengandung pigmen yang juga berfungsi sebagai antioksidan kuat, antara lain betasianin dan likopen. Antioksidan tersebut bisa melindungi tubuh dari radikal bebas, mencegah penyakit kardiovaskuler, juga berfungsi anti-inflamasi. Sayangnya, khasiat antioksidan tersebut mudah berkurang akibat pemanasan. Oleh karena itu kalau kita ingin mendapatkan manfaat optimal antioksidannya, buah naga sebaiknya dikonsumsi dalam keadaan segar atau dalam bentuk makanan yang tidak melibatkan proses pemanasan. Jangan khawatir jika pigmen merah ini membuat air kecil dan air besar kita berwarna merah ini tidak berbahaya.

Hasil ekstraksi didapat rendemen ekstrak sebesar $8,25 \%$ yang menunjukan tersari pigmen warna sebanyak 8,25 bagian dari 100 bagian sampel yang diekstraksi. Rendemen yang didapat lebih rendah dibandingkan ubi jalar ungu karena buah naga mengandung lebih banyak air, sehingga kandungan air yang tinggi menambah bobot sampel. Pada ubi jalar ungu dihasilkan ekstrak kental dengan warna ungu tua dan bau khas ubi jalar. Bau khas ubi jalar berbeda dengan bau ekstrak buah naga karena pada ubi jalar tidak terkandung asam sitrat dan kadar gula ubi jalar lebih rendah. Rendemen ubi jalar ungu sebesar $19,45 \%$ yang menunjukan tersari 19,45 bagian pigmen warna dari 100 bagian ubi jalar ungu yang 
digunakan. Rendemen ubi jalar ungu lebih besar karena ubi jalar ungu mengandung kadar air yang lebih rendah dibanding buah naga.

Seperti yang dilansir di NY Daily News (11/09/2013), seorang ahli kimia makanan dari Texas A\&M Stephen T. Talcott, pada pertemuan American Chemical Society, menyebutkan bahwa ubi ungu bisa jadi pewarna alami. Karena ubi ungu ini memiliki pigmen antosianin yang sama seperti yang ditemukan pada ceri hitam dan jenis angguranggur lainnya. Dibandingkan dengan buahbuahan yang mengandung pigmen antosianin lainnya, ubi ungu memiliki rasa yang relatif netral. Karenanya tidak akan merusak rasa makanan yang akan diberi pewarna.

\section{KESIMPULAN DAN SARAN}

Kesimpulan yang terdapat pada penelitian ini adalah berdasarkan hasil pengujian sifat fisik dapat diketahui bahwa pada formulasi gel ekstrak konsentrasi $60 \%$ memenuhi persyaratan sifat fisik gel, gel dari ekstrak buah naga dan ubi jalar ungu memiliki nilai LC50 sebesar 2352,39 $\mu \mathrm{g} / \mathrm{ml}$ dan 1805,69 $\mu \mathrm{g} / \mathrm{ml}$, sehingga aman digunakan berdasarkan uji BSLT dan kemampuan ekstrak gel buah naga dan umbi jalar ungu sebagai pewarnaan plak gigi secara deskripsi sama-sama mempunyai kemampuan namun buah naga sedikit kemampuannya lebih baik namun secara statistik tidak signifikan. Saran yang dapat diberikan berdasarkan penelitian ini, yaitu: dilakukan penelitian lanjutan terkait pengujian iritasi pada kulit, dilakukan penelitian lanjutan terkait uji stabilitas dari gel ekstrak buah naga dan gel ekstrak ubi jalar ungu, diharapkan untuk penelitian lanjutan untuk membuat ekstrak gel buah naga dan ubu jalar ungu ini agar dapat bertahan lebih lama atau lebih awet dan disarankan untuk identifikasi plakskor menggunakan kedua ekstrak gel tersebut karena sama-sama dapat mendeteksi plak skor dan berbahan dasar alami tidak menggunakan bahanbahan kimia

\section{UCAPAN TERIMA KASIH}

Ucapan terima kasih disampaikan kepada Kementerian Kesehatan Republik Indonesia yang telah memberikan dukungan biaya dalam penelitian. Ucapan terima kasih juga disampaikan kepada seluruh pihak yang terlibat dalam penelitian ini; dosen dan staf laboratorium Jurusan Teknik Laboratorium Medik Banjarmasin.

\section{DAFTAR PUSTAKA}

1. Putri MH, Herijulianti E, Nurjannah N. Ilmu Pencegahan Penyakit Jaringan Keras dan Jaringan Pendukung Gigi Jakarta: EGC; 2013.

2. Kidd EAM, Fejerskov O. Essentials of Dental Caries. 4th ed. Hampshire: Oxford Uneversity Press; 2016.

3. Putri MH, Herijulianti E, Nurjannah N. Ilmu Pencegahan Penyakit Jaringan Keras dan Jaringan Pendukung Gigi Jakarta: EGC; 2013

4. Sukmawati S. Perbedaan Kemampuan Penggunaan Larutan Ubi Jalar Ungu dengan Buah Bit Sebagai Bahan Identifikasi Plak. [Online].; 2016 [cited 2017 January 11. Available from: http:// ejournal.poltekkessmg.ac.id/ojs/index.php/kepk/article/view/ 553.

5. Bellec FL, Fabrice V, Eric I. Pitahaya (Hylocereus spp.): a new fruit crop, a market with a future. Fruits 61. 2006;: p. 237-250.

6. Martirosyan DM. Functional Foods for Chronic Diseases USA: DEA Inc; 2006.

7. Povakovic D, Marijana K. Complex Biochemistry and Biotechnological Production of Betalains. Food Technol. Biotechnol 49 (2). 2011;: p. 145-155.

8. Sugiyono. Metode Penelitian Bisnis. Bandung : Alfabeta; 2012.

9. Darwis, D, Hardiningsih, L, dan Nurlidar, F. Karakteristik Sifat Fisika - Kimia Hidrogel PVP-Madu-Gliserin Hasil Iradiasi Gamma; 2011; ISSN 1907-0322

10. Lachman, L., \& Lieberman, H. A. Teori dan Praktek Farmasi Industri, Edisi Kedua, 10911098, UI Press: Jakarta; 1994. 